\title{
THE TEN TALES
}

1. The First Slaughtering 5

2. From the Yard of Blood to the Yard of the Woman in Red 50

3. Cupid with His Arrows 80

4. Lively Souls and Siankes, Their Shadows 141

5. The Black Shoes, Dekatessara ... 170

6. Rapinas Nocturnas (It Wasn't a Winter's Tale) 220

7. The Bell-Wearers; Velvety and the Werewolf 264

8. "An Evil Angel Passed by and Thought It Good to Touch Me" 336

9. "The Winds Were Blowing from All Quarters and the Tortoise Went with the Candle on Its Back" 405

10. "The Bird and the Crumb" 480 
This page intentionally left blank 